\title{
Vaginal Endocervicosis
}

National Cancer Institute

\section{Source}

National Cancer Institute. Vaginal Endocervicosis. NCI Thesaurus. Code C128066.

A rare benign lesion characterized by the presence of endocervical-type glands in the vaginal wall. 